\title{
Study on the Estimation of Proper Compression Ratios for Korean Domestic Wood Species by Single Pellet Press ${ }^{1}$
}

\author{
Hyoung-Woo LEE ${ }^{2, \dagger} \cdot$ Soon-Bae $\mathrm{KIM}^{3}$
}

\begin{abstract}
Single pellet press technology allows for fast, low-cost, and small-scale tests to investigate pelletizing characteristics. We estimated proper compression ratios for five Korean domestic wood species through predicted relationships between pelletizing pressure $P_{x}$ and compression ratio based on experimental data obtained from a single pellet press unit. The pressures required to obtain a 6-mm-diam pellet of density $1200 \mathrm{~kg} / \mathrm{m}^{3}$ were estimated as $111 \mathrm{MPa}$ for Populus davidiana, $133 \mathrm{MPa}$ for Robinia pseudoacacia, $136 \mathrm{MPa}$ for Quercus mongolica, $97 \mathrm{MPa}$ for Pinus densiflora, and $127 \mathrm{MPa}$ for Pinus rigida. On the basis of these pressures, we estimated proper compression ratios to be within the range 7.676-8.410 for these species, and we found the compression ratios needed for hardwood species to be somewhat higher than those needed for softwood species to obtain the pellet density of $1200 \mathrm{~kg} / \mathrm{m}^{3}$.
\end{abstract}

Keywords: wood pellet, single pellet press, compression ratio, pelletizing pressure, pellet density, Korean domestic wood species

\section{INTRODUCTION}

Pelletization of biomass is considered to provide a consistent quality, high energy content and uniform size and shape solid energy carrier that facilitates the logistics of biomass. Biomass can be compressed into pellets when mechanical pressure is applied to the biomass to crush its cellular structure. Typical unit densities of biomass pellets can be as high as 1000 to $1400 \mathrm{~kg} / \mathrm{m}^{3}$ with average of $1200 \mathrm{~kg} / \mathrm{m}^{3}$, and the bulk densities are about $700 \mathrm{~kg} / \mathrm{m}^{3}$ (Sokhansanj and Turhollow, 2004).

It is necessary to know about the physical forces that build up in the press channel of a pellet mill to understand and optimize the biomass pelletizing process. Pellets are produced in a pellet mill that generally consists of a die with cylindrical press channels and rollers that force the biomass to flow into and through these channels. The physical forces built up in the press channel of pellet mill are mainly due to the friction between press channel wall and biomass. Therefore, determination of these physical forces is crucial for understanding and optimizing the pelletizing process. Basically optimization of pelletizing process conditions through the expensive and time-consuming "trial and error" experiments is the only way

\footnotetext{
${ }_{1}^{1}$ Date Received March 23, 2020, Date Accepted May 8, 2020

${ }^{2}$ College of Agriculture and Life Science, Chonnam National University, Gwangju 61186, Republic of Korea

${ }^{3}$ Hansol HomeDeco Co., Ltd., Seoul 07071, Republic of Korea

† Corresponding author: Hyoung-Woo LEE (e-mail: dryingeng@daum.net, ORCID: 0000-0001-6451-325X)
} 
Study on the Estimation of Proper Compression Ratios for Korean Domestic Wood Species by Single Pellet Press

to produce stable pellets. Yang et al. (2017) investigated the effect of length to diameter ratio of a hole in flat die pelletizer on the characteristics of four Korean domestic wood species. Recently, a single pellet press allows for fast and low-cost tests in very small scale to investigate the pelletizing characteristics. This technology has been used in various pelletizing studies and proven its practicability (Puig-Arnavat et al, 2016). Lee et al. (2011) investigated pellet qualities of two Korean wood species, Larix kaempferi C. and Liriodendron tulipifera L. using piston-type single pellet press.

Nielsen et al. (2009) found that the important pelletizing parameters were biomass species, temperature, moisture content, fiber orientation, and raw material extractive content through their extensive studies. However, their studies were based on short pellets of a few millimeters in length. Therefore, the challenge in biomass pelletization is to know how the controllable process parameters affect the pelletizing pressure $P_{x}$ in commercial pellet mill. This knowledge will help selecting proper pelletizing conditions in real situations. In case $P_{x}$ exceeds the certain proper range and becomes too high, the pellet die holes will be plugged. On the other hand, at too low $P_{x}$ pellets with acceptable quality cannot be produced.

The pelletizing pressure acting in a press channel of pellet mill die can mathematically be expressed as following equation (Stelte et al, 2011a):

$$
P_{x}=\frac{P_{N 0}}{v_{L R}}\left(e^{4 \mu v_{L R} c}-1\right)
$$

where $P_{N 0}, v_{L R}, \mu$, and $c$ is a pre-stressing pressure incorporating plasticity in the model, the Poisson's ratio, the friction coefficient, and the compression ratio, respectively. The first index $L$ and the second index $R$ denotes the direction of applied stress (longitudinal fiber axes) and transverse deformation (radial fiber axes), respectively. The compression ratio $c$ is defined as the ratio between the length and diameter of the pellet on the die.

Unfortunately, values of $v_{L R}$ and $\mu$ are not available in the literature for all type of biomass and not available for different temperatures and moisture contents, either. Furthermore, the material specific parameter $P_{N 0}$ can only be determined experimentally. Stelte et al. (2011a) identified that compression ratio $c$ was one of the key parameters affecting $P_{x}$. Therefore, Stelte (2011b) proposed the simple method that allowed faster testing of new types of biomass by easy estimation of the compression curves ( $P_{x}$ vs. $c$ ) up to compression ratios relevant for commercial pellet mills using single pellet press.

The object of this study was to predict proper compression ratios for five Korean domestic wood species through the predictions of relationships between $P_{x}$ and $c$ based on the experimental data using a single pellet press (SPP) unit.

\section{MATERIALS and METHODS}

\subsection{Material preparation}

Five Korean domestic wood species were used for this study: Populus davidiana, Quercus mongolica, Robinia pseudoacacia, Pinus densiflora, and Pinus rigida. All materials were provided as green sawdust by Yongsan Sawdust Co., Namwon, Korea. Green sawdusts were air-dried to moisture contents of about $10 \%$ for longer than 2 weeks. Moisture contents of air-dried sawdust were $10.2 \%, 10.6 \%, 11.4 \%, 9.3 \%$, and $11.7 \%$ for Quercus mongolica, Populus davidiana, Pinus rigida, Pinus densiflora and Robinia pseudoacacia, respectively. Air-dried sawdusts were comminuted into particles using knife mill (Model No. LKM2015, Drying Engineering, Inc., Korea) equiped with a 3.75 
$\mathrm{kW}$ electric motor with a rotation speed of $1720 \mathrm{rpm}$. Particles were separated by sieve shaker and only the particles smaller than $1 \mathrm{~mm}$ were selected. Prior the tests the selected materials were kept in air tight plastic bags.

\subsection{Single pellet press}

Single pellet press was basically composed of worm gear jack screw with stroke of $200 \mathrm{~mm}$ and gear reduction ratio of 1/6 (Model No. SJ44, Samyang Reduction Gear Co., Ltd.), $0.75 \mathrm{~kW}$ geared motor with gear reduction ratio of 1/75 (Model No. MG-F153, Samyang Reduction Gear Co., Ltd.), load cell with capacity of 100 kN (Model No. SUL-10T, Sentech Co., Ltd.) and cylindrical single die made of hardened steel (Fig. 1). Die with diameter of $26 \mathrm{~mm}$ and length of $70 \mathrm{~mm}$ was lagged with heating elements and thermal insulation (Fig. 2). K-type thermocouple temperature sensor was inserted into this die to maintain uniform temperature during pelletizing process. Maximum pressure, compression rate, die temperature, and pressure holding time were controlled by programmable logical controller (PLC). And all the data was collected by data logging system to monitor the applied load and displacement during compression process. This enabled a better analysis of the behaviour of

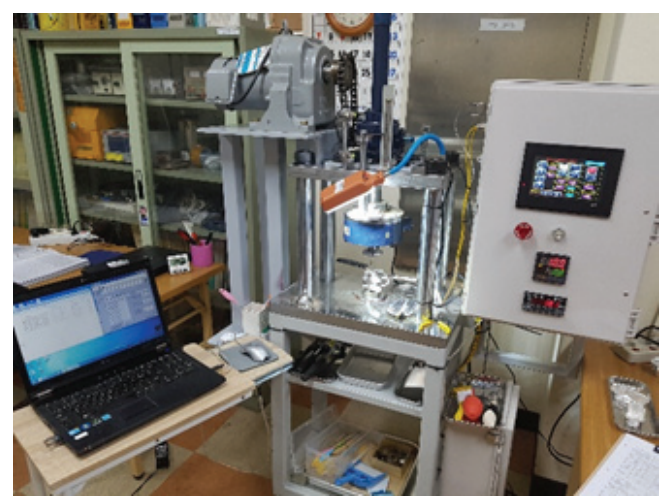

Fig. 1. Single pellet press.

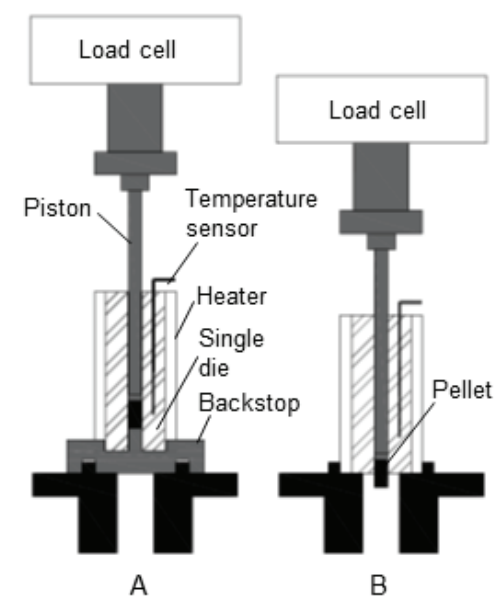

Fig. 2. Structure of single die (A: Compressing pellet; B: Discharging pellet).

friction forces generated between pellet and the wall of the press channel.

Pressure was applied using metal piston with diameter of $5.8 \mathrm{~mm}$ for $6 \mathrm{~mm}$ press channel diameter of die. The end of die could be closed using a backstop and the force was measured using a load cell. The press channel was wiped clean, using a brush, when changing raw materials and each test was repeated three times to minimize the experimental error.

\subsection{Pelletizing test procedure}

To simulate the pelletizing process within a pellet mill, the pellet has to be built up in sequential layers. To determine the proper pressure for unit pellet density of $1200 \mathrm{~kg} / \mathrm{m}^{3}, 0.2 \mathrm{~g}$ of material was loaded into press channel at the first charge and compressed. Then the piston was removed and the second charge of 0.2 $\mathrm{g}$ of material was loaded and compressed again. Temperature of die was maintained at $100^{\circ} \mathrm{C}$ during the compression process and the pressure was released after 10 seconds of retention to stabilize the pressure in press channel at each charge. After the second compression was finished, backstop of press channel was 
removed. Then pellet was pushed out from press channel by piston and mass of pellet was measured. Applied pressures were 50, 100, 200, and $300 \mathrm{MPa}$ at pressing rate of $5 \mathrm{~mm} / \mathrm{min}$. Typically, die temperature is between $100 \sim 130^{\circ} \mathrm{C}$, and the pressure is between $120 \sim 300 \mathrm{MPa}$ for commercial pellet mill (Whittaker and Shield, 2017).

Mass was measured by using an electrical balance with an accuracy of $\pm 0.001 \mathrm{~g}$. Volume was calculated from the diameter and length of pellet using an electronic caliper with an accuracy of $\pm 0.01 \mathrm{~mm}$, assuming a perfectly cylindrical shape. Pellet density was determined immediately following the ejection of the pellets. The pressure $P_{d}$ to get the pellet density of $1200 \mathrm{~kg} / \mathrm{m}^{3}$ was estimated with the relationship between applied pressures and pellet densities for each species.

The pelletizing process was same as the process for determining the proper pressure as above. After the pellet was compressed, backstop of press channel was removed and $P_{x}$ was determined by measuring the maximum pressure required to press the pellet out of the press channel (Fig. 2). $P_{x}$ was defined as the pelletizing pressure acting in a press channel of pellet mill die in Eq. (1) and mainly due to the friction between pellet and wall of press channel. Therefore, the maximum force needed for the piston to press out the pellet could be read as the highest force generated in press channel, $P_{x}$.

The increment of compression ratio $c$ was simulated by increasing the length of pellet formed in press channel with increasing the mass of raw material loaded into press channel. For the determination of $P_{x}$ according to $c$, material loading per charge was increase from $0.2 \mathrm{~g}$ to $0.6 \mathrm{~g}$ with increment of $0.1 \mathrm{~g}$. As material loading increased, lengths of pellet in press channel also increased with the same diameter of pellet. This means the increase of compression ratio $c$ (Fig. 3).

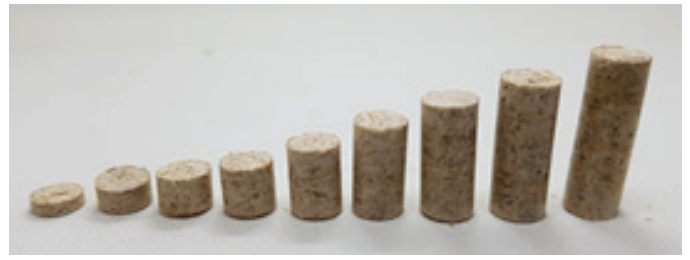

Fig. 3. The increment of pellet length to simulate the increment of compression ratio.

Diameters and lengths of pellets were measured to calculate compression ratios and the relationship between $P_{x}$ and $c$ was determined for each species. Finally, the proper compression ratio was estimated by applying the pressure $P_{d}$ for the target pellet density of $1200 \mathrm{~kg} / \mathrm{m}^{3}$ to the relationship of $P_{x}$ vs. $c$, assuming $P_{d}=P_{x}$.

\section{RESULTS and DISCUSSION}

\subsection{Pressures and pellet densities}

Table 1 shows the pellet densities at various pressure levels for each wood species. The relationships between applied pressures and pellet densities for each species were modified for linearization using natural logs as Eq. (2)(Fig. 4). Then the pressure $P_{d}$ to get the pellet with density of $1200 \mathrm{~kg} / \mathrm{m}^{3}$ was estimated for each species as Table 2.

$$
\ln (\rho)=m \ln (P)+b
$$

where $\rho, P, m$, and $b$ is pellet density, applied pressure, slope, and intercept of line, respectively.

As applied pressure was increased, pellet density was also increased for all the species as expected. The pressures required to obtain the $6 \mathrm{~mm}$-diameter pellet with density of $1200 \mathrm{~kg} / \mathrm{m}^{3}$ were estimated as 111 , 133, 136, 97, and $127 \mathrm{MPa}$ for Populus davidiana, Robinia pseudoacacia, Quercus mongolica, Pinus densiflora, and Pinus rigida, respectively (Table 2). It was 
Table 1. Pellet densities of $6 \mathrm{~mm}$-diameter according to the applied pressure and wood species

(Unit : $\mathrm{kg} / \mathrm{m}^{3}$ )

\begin{tabular}{cccccc}
\hline \multirow{2}{*}{$\begin{array}{c}\text { Pressure } \\
(\mathrm{MPa})\end{array}$} & $\begin{array}{c}\text { Populus } \\
\text { davidiana }\end{array}$ & $\begin{array}{c}\text { Quercus } \\
\text { mongolica }\end{array}$ & $\begin{array}{c}\text { Robinia } \\
\text { pseudoacacia }\end{array}$ & $\begin{array}{c}\text { Pinus } \\
\text { densiflora }\end{array}$ & $\begin{array}{c}\text { Pinus } \\
\text { rigida }\end{array}$ \\
\hline \hline 50 & 1120 & 1121 & 1121 & 1176 & 1170 \\
100 & 1202 & 1186 & 1191 & 1203 & 1201 \\
200 & 1267 & 1231 & 1231 & 1214 & 1212 \\
300 & 1280 & 1264 & 1252 & 1257 & 1223 \\
\hline
\end{tabular}

Table 2. Slope (m), intercept (b), and $\mathrm{R}$ of linearized relationship between applied pressure and $6 \mathrm{~mm}$-diameter pellet density, and the estimated pressure for pellet density of $1200 \mathrm{~kg} / \mathrm{m}^{3}$ for five Korean domestic wood species

\begin{tabular}{cccccc}
\hline & \multicolumn{5}{c}{ Wood species } \\
\cline { 2 - 6 } Item & $\begin{array}{c}\text { Populus } \\
\text { davidiana }\end{array}$ & $\begin{array}{c}\text { Quercus } \\
\text { mongolica }\end{array}$ & $\begin{array}{c}\text { Robinia } \\
\text { pseudoacacia }\end{array}$ & $\begin{array}{c}\text { Pinus } \\
\text { densiflora }\end{array}$ & $\begin{array}{c}\text { Pinus } \\
\text { rigida }\end{array}$ \\
\hline \hline $\mathrm{m}$ & 0.076 & 0.066 & 0.061 & 0.033 & 0.024 \\
$\mathrm{~b}$ & 6.556 & 6.618 & 6.651 & 6.862 & 6.922 \\
$\mathrm{R}^{2}$ & 0.967 & 0.992 & 0.970 & 0.896 & 0.950 \\
$P_{d}(\mathrm{MPa})$ & 111 & 133 & 136 & 97 & 127 \\
\hline
\end{tabular}

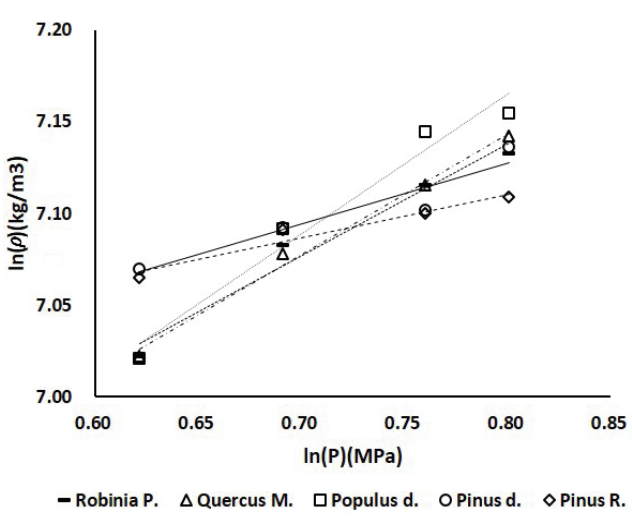

Fig. 4. Relationships between pressures and pellet densities for five Korea domestic wood species.

found that pressure below $140 \mathrm{MPa}$ was enough to obtain the $6 \mathrm{~mm}$-diameter pellet with density of 1200 $\mathrm{kg} / \mathrm{m}^{3}$ for these five species. Seo et al. (2015) reported the densities of pellets produced by a flat-die pellet mill were 1324 and $1249 \mathrm{~kg} / \mathrm{m}^{3}$ for Pinus densiflora and Pinus rigida, respectively.

\subsection{Pelletizing pressures}

Fig. 5 and Fig. 6 shows the pellet discharging pressure curve for Quercus mongolica and Pinus densiflora, respectively. Maximum pellet discharging pressure was higher for Quercus mongolica than Pinus densiflora. There were strong fluctuations on pellet discharging pressure curve for Pinus densiflora. Pinus rigida showed strong fluctuations, too. Pellet discharging pressure is mainly composed of adhesive friction and sliding friction (Nguyen et al., 2015). Therefore, higher contents of cohesive components in two softwood species than other three hardwood species seem to be the main reason for these fluctuations. It is needed to investigate the differences in cohesive components content between these species.

The exponential dependency of maximum pellet discharging pressure $P_{x}$ on compression ratio $c$ for five Korean domestic wood species is shown in Fig. 7. The model fit to the experimental data was made 


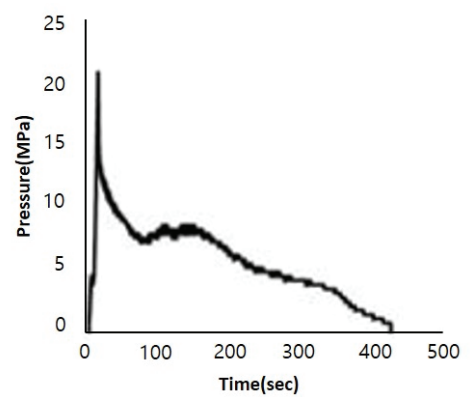

Fig. 5. Pellet discharging pressure curve for Quercus mongolica.

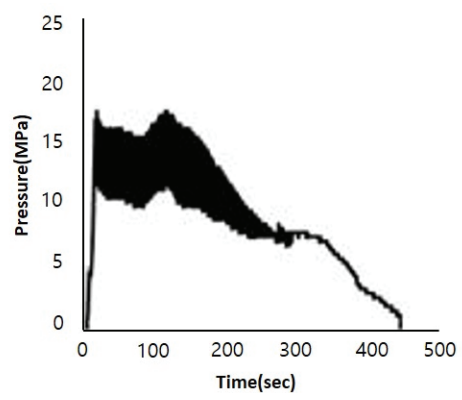

Fig. 6. Pellet discharging pressure curve for Pinus densiflora.

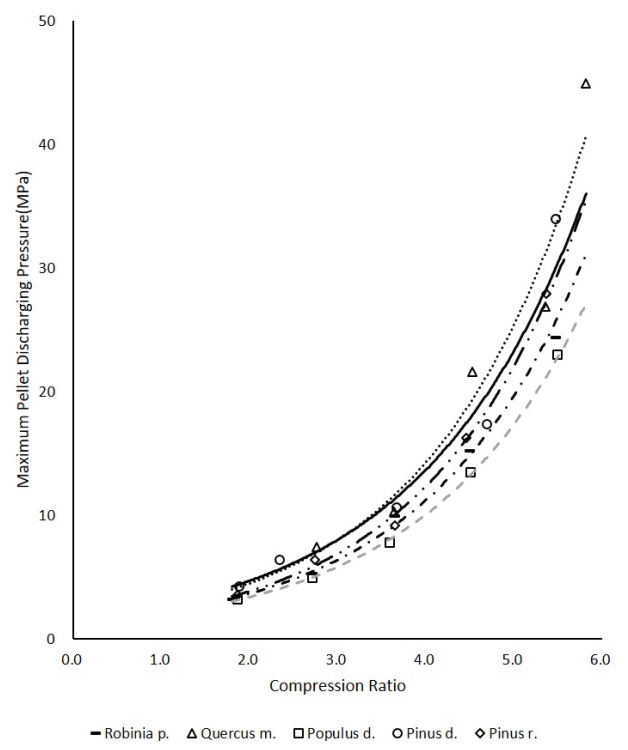

Fig. 7. Relationships between compression ratios and maximum pellet discharging pressures for five Korea domestic wood species. to show the exponential increase in $P_{x}$ as a function of $c$. Range of $c$ and $P_{x}$ was $1.8 \sim 5.8$ and $23 \sim$ $45 \mathrm{MPa}$, respectively. $P_{x}$ was the maximum pressure loaded as the pellet was pushed out from press channel. $P_{x}$ was increased and increasing rate of $P_{x}$ was higher as $c$ was increased for all five species. There were differences in increasing rate of $P_{x}$ among five species. The increasing rates of $P_{x}$ for Quercus mongolica and Robinia pseudoacacia were somewhat higher than those for Pinus densiflora and Pinus rigida. As the poison ratio of hardwood species is generally higher than softwood species, stronger expanding force perpendicular to press channel wall is developed in hardwood species than softwood species when they are compressed in press channel (Holm et al., 2006). This expending force causes friction between pellet and press channel wall and increases the pressure required to push out pellet from press channel.

Other reason for the lower pressure required to push out pellet from press channel for softwood than hardwood species seems to be the higher extractives content of softwoods. A study suggests that wood extractives, a wide range of chemical compounds such as resin compounds, fatty acids, waxes and sterols, might act as lubricants in the press channel, and therefore reduce the friction between pellet and press channel wall (Finell et al., 2009; Carly and Shield, 2017). Ahn et al. (2013a) reported that pellet production yield was higher for Larix kaempferi C. than mixed hardwoods at the same pelletizing conditions.

\subsection{Compression ratios}

It has been shown that the pelletizing pressure $P_{x}$ increases exponentially with pellet length, Results of regression analysis between compression ratios $c$ and the pelletizing pressure $P_{x}$ was shown in Table 3 . Compression ratios at the pressure to obtain the pellet 
Table 3. Results of regression analysis on $P_{x}$ ( $y$ in eq.) vs. $c$ ( $x$ in eq.) and estimated compression ratio $c$ at $P_{d}$ for $6 \mathrm{~mm}$-diameter pellet of five Korean domestic wood species

\begin{tabular}{lccc}
\hline \multicolumn{1}{c}{ Species } & Regression equation & $\mathrm{R}^{2}$ & $c_{d}$ at $P_{d}$ \\
\hline \hline Populus davidiana & $y=11.321 e^{0.546 x}$ & 0.999 & 8.361 \\
Quercus mongolica & $y=14.197 e^{0.577 x}$ & 0.971 & 7.838 \\
Robinia pseudoacacia & $y=11.851 e^{0.562 x}$ & 0.997 & 8.410 \\
Pinus densiflora & $y=16.181 e^{0.533 x}$ & 0.979 & 7.676 \\
Pinus rigida & $y=12.043 e^{0.582 x}$ & 0.995 & 7.975 \\
\hline
\end{tabular}

density of $1200 \mathrm{~kg} / \mathrm{m}^{3}, c_{d}$, were also estimated for five Korean domestic wood species. For example, Pinus densiflora needed the lowest $c_{d}$ of 7.676 among these five species. Many of major pellet mill manufacturers in the world recommend $7.0 \sim 8.0$ for pine wood pellet as the optimal compression ratio (Gemco Energy Co., Ltd., NA). Therefore, single pellet press technology is expected to be possible to estimate proper compression ratios for the pelletization of wood species.

When pelletizing wood biomass, hardwood species generally require lower compression ratios than softwood species because the back-pressure increases faster for hardwood than softwood species. This differences in back-pressure are not fully understood, and they are likely caused by the fundamental differences in structures and chemical compositions (Holm et al., 2006). However, in this results hardwood species needed somewhat higher compression ratios to obtain the pellet density of $1200 \mathrm{~kg} / \mathrm{m}^{3}$ than softwood species. This means that hardwood species need higher pelletizing pressures than softwood species for the same pellet density. High compression ratios induce higher friction forces in press channel and too high friction forces result in plugging of press channel. If lower compression ratios were applied for hardwood species, pellets with lower densities would be produces. Ahn et al. (2013b) could enhance the bulk density of pellets from $645 \mathrm{~kg} / \mathrm{m}^{3}$ to $662 \mathrm{~kg} / \mathrm{m}^{3}$ by adding lignin powder as binder for Liriodendron tuli- pifera $\mathrm{L}$. . Therefore, it is recommended to add binders or lubricants when high compression ratio is needed. Mixing softwood species with hardwood species also can be one of other solutions to lower the proper compression ratios of hardwood species.

\section{CONCLUSION}

Single pellet press was used to estimate the proper compression ratios to obtain a target pellet density $1200 \mathrm{~kg} / \mathrm{m}^{3}$ for five Korean domestic wood species. It was found that the proper compression ratios were estimated as $8.410 \sim 7.676$ for five wood species and hardwood species needed somewhat higher compression ratios than softwood species, as expected. Compression ratio estimated for Pinus densiflora was 7.676 and compression ratio of $7 \sim 8$ is generally recommended for most commercial pellet mills. Therefore, optimization of pelletizing process conditions through this simple single pellet press technology can be expected to avoid the expensive and time-consuming "trial and error" experiments which have been the only way to produce stable pellets so far.

\section{REFERENCES}

Ahn, B.J., Kim, Y.S., Lee, O.K., Cho, S.T., Choi, D.H., Lee, S.M. 2013a. Wood pellet production using 
Study on the Estimation of Proper Compression Ratios for Korean Domestic Wood Species by Single Pellet Press

domestic forest thinning residues and their quality characteristics. Journal of the Korean Wood Science and Technology 41(4): 346-357.

Ahn, B.J., Chang, H.S., Cho, S.T., Han, G.S., Yang, I. 2013b. Effect of the addition of binders on the fuel characteristics of wood pellets. Journal of the Korean Wood Science and Technology 41(6): 465-489.

Carly, W., Shield, I. 2017. Factors affecting wood, energy grass and straw pellet durability. Renewable and Sustainable Energy Reviews Volume 71: 1-11.

Finell, M., Arshadi, M., Gref, R., Scherzer, T., Knolle, W., Lestander, T. 2009. Laboratory-scale production of biofuel pellets from electron beam treated Scots pine (Pinus silvestris L.) sawdust. Radiat. Phys. Chem. 78: 281-287.

Gemco Energy Co., Ltd., NA. What's the compression ratio of wood pellet machine. www.gemcopelletmills.com.

Holm, J.K., Henriksen, U.B., Hustad, J.E. 2006. Toward an understanding of controlling parameters in softwood and hardwood pellets production. Energy Fuels 20: 2686-2694.

Lee, S.M., Choi, D H., Cho, S.T., Nam, T.H., Han, G.S. Yang, I. 2011. Effects of various factors on the durability of pellets fabricated with Larix kaempferi C. and Liriodendron tulipifera L. sawdust. Journal of the Korean Wood Science and Technology 39(3): 258-268.

Nguyen, Q.N., Cloutier, A., Achim, A., Stevanovic, T. 2015. Effect of process parameters and raw material characteristics on physical and mechanical properties of wood pellets made from sugar maple particles. Biomass and Bioenergy 80: 338-349.

Nielsen, N.P. K., Gardner, D.J., Poulsen, T., Felby, C. 2009. Importance of temperature, moisture content, and species for the conversion process of wood into fuel pellets. Wood Fiber Sci. 41: 414-425. Puig-Arnavat, M., Shang, L., Sarossy, Z., Ahrenfeldt, J., Henriksen, U.B. 2016. From a single pellet press to a bench scale pellet mill - Pelletizing size different biomass feedstocks. Fuel Processing Technology 142: 27-33.

Seo, J.W., Lee, E.S., Kang, C.Y., Kim, S.B., Yoon, Y.H., Park, H. 2015. Comparison of quality characteristics of wood pellet manufactured from Pinus densiflora S. et Z. and Pinus rigida Mill. Journal of the Korean Wood Science and Technology 43(3): 374-380.

Sokhansanj, S., Turhollow, A.F. 2004. Biomass densification - Cubing operations and costs for corn stover. Applied Engineering Agriculture 20: 495-499.

Stelte, W., Holm, J.K., Sanadi, A.R., Barsberg, S., Ahrenfeldt, J., Henriksen, U.B. 2011a. Fuel pellets from biomass: The importance of the pelletizing pressure and its dependency on the processing conditions. Fuel 90(11): 3285-3290.

Stelte, W. 2011b. Fuel Pellets from Biomass. Processing, Bonding, Raw Materials. Roskilde: Technical University of Denmark. Risø-PhD, No. 90(EN).

Whittaker, C., Shield, I. 2017. Factors affecting wood, energy grass and straw pellet durability - A review. Renewable \& Sustainable Energy Reviews 71: $1-11$.

Yang, I., Kim, S.H., Han, G.S. 2017. Effect of moisture content of sawdust and length to diameter ratio of a hole in flat-die pelletizer on the fuel characteristics of wood pellets produced with Quercus mongolica, Pinus densiflora, Pinus rigida and Larix kaempferi. Journal of the Korean Wood Science and Technology 45(4): 382-398. 